\title{
Reactor Pressure Vessel Temperature Analysis For Prismatic And Pebble-Bed VHTR Designs
}

\author{
H. D. Gougar \\ C. B. Davis
}

April 2006

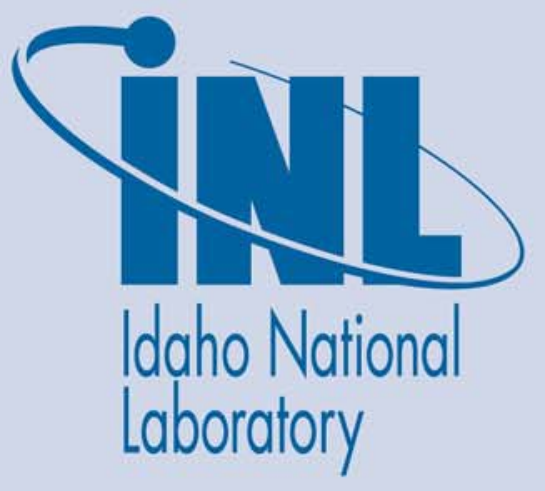

The INL is a U.S. Department of Energy National Laboratory operated by Battelle Energy Alliance 



\title{
Reactor Pressure Vessel Temperature Analysis for Prismatic and Pebble-Bed VHTR Designs
}

\author{
H. D. Gougar and C. B. Davis
}

April 2006

Idaho National Laboratory

Idaho Falls, Idaho 83415

Prepared for the

U.S. Department of Energy

Assistant Secretary for Nuclear Energy

Under DOE Idaho Operations Office

Contract DE-AC07-05ID14517 


\begin{abstract}
Analyses were performed to determine maximum temperatures in the reactor pressure vessel for two potential Very-High Temperature Reactor (VHTR) designs during normal operation and during a depressurized conduction cooldown accident. The purpose of the analyses was to aid in the determination of appropriate reactor vessel materials for the VHTR. The designs evaluated utilized both prismatic and pebble-bed cores that generated $600 \mathrm{MW}$ of thermal power. Calculations were performed for fluid outlet temperatures of 900 and $950{ }^{\circ} \mathrm{C}$, corresponding to the expected range for the VHTR. The analyses were performed using the RELAP5-3D and PEBBED-THERMIX computer codes. Results of the calculations were compared with preliminary temperature limits derived from the ASME pressure vessel code.
\end{abstract}




\section{SUMMARY}

The expected high operating temperatures of the Very High Temperature Reactor (VHTR) place significant constraints on the choice of materials for the reactor pressure vessel. Current designs based on the Pebble Bed Modular Reactor (PBMR) propose using SA-508 steel for the reactor vessel while those based on the Gas-Turbine Modular Helium Reactor (GT-MHR) propose using SA-336 (9Cr-1Mo-V). SA-508 steel has been used for reactor vessels in light water reactors and is expected to be significantly cheaper than SA-336.

Analyses were performed to determine maximum temperatures in the reactor pressure vessel for two potential VHTR designs during normal operation and during a depressurized conduction cooldown accident. The purpose of the analyses was to aid in the determination of appropriate reactor vessel materials for the VHTR. The VHTR designs evaluated utilized both prismatic and pebble-bed cores. The cores generated $600 \mathrm{MW}$ of thermal power and had fluid outlet temperatures of either 900 or $950{ }^{\circ} \mathrm{C}$. The analyses of the prismatic design were performed using the RELAP5-3D computer code, while the analyses of the pebble-bed design were performed with the coupled PEBBED-THERMIX. Because PEBBED-THERMIX has not been extensively validated, confirmatory calculations were also performed with RELAP5-3D for the pebble-bed design. During normal operation, the predicted axial profiles in reactor vessel temperature were similar with both codes, but the maximum value predicted by PEBBEDTHERMIX was about $40^{\circ} \mathrm{C}$ higher than the corresponding value predicted by RELAP5-3D. The trends of the calculated vessel temperatures were similar during the depressurized conduction cooldown accident and the maximum calculated values were within $13{ }^{\circ} \mathrm{C}$. This agreement is considered reasonable based on the expected uncertainty in either calculation.

Table I summarizes the results of the calculations with preliminary temperature limits from the ASME pressure vessel code. The temperature limits are considered preliminary because not all factors, such as reductions to account for welds and operating history, have been accounted for. Calculated results for normal operation are presented in the second or third columns of Table I. Calculated results for the depressurized conduction cooldown accident are presented in the last column.

Table I shows that SA-508 is not a suitable material for the prismatic VHTR based on its current design. The maximum temperature during normal operation exceeds the value that allows unlimited operating time with SA-508 steel. The calculations show that SA-336 steel is suitable for the prismatic design and allows 34 years of normal operation with considerable margin. Additional work will be required to extend the design lifetime to the 40 to 60 years typically desired for nuclear plants. A more detailed design of the lower head region is also required. The current design provides a large margin to the 1000-h limit of $650{ }^{\circ} \mathrm{C}$ for SA-336 during the depressurized conduction cooldown accident. In fact, the maximum calculated temperatures during the accident meet the $590-{ }^{\circ} \mathrm{C}$ limit for normal operation.

For the pebble-bed design, the maximum vessel temperature during normal operation was $21{ }^{\circ} \mathrm{C}$ above the allowed value for unlimited operation of SA-508 based on the PEBBED-THERMIX calculation, but was $16{ }^{\circ} \mathrm{C}$ below the temperature limit based on the PEBBED-THERMIX calculation. Design changes, such as the use of active cooling of the lower vessel, are required to reduce the maximum temperature below the allowed value and/or to increase the margin to the temperature limit during normal operation. The maximum calculated temperatures with both codes were significantly below the allowed values during the depressurized conduction cooldown accident. 
Table I. A comparison of temperature limits and maximum calculated reactor vessel temperatures.

\begin{tabular}{|l|c|c|c|c|}
\hline & \multicolumn{3}{|c|}{ Operation } \\
\hline & Unlimited & $<3 \times 10^{5} \mathrm{~h}$ & $<3000 \mathrm{~h}$ & $<1000 \mathrm{~h}$ \\
\hline & & & & \\
\hline Prismatic core: & & & & $590<\mathrm{T}<650^{\circ} \mathrm{C}$ \\
\hline $\begin{array}{l}\text { SA-336 } \\
(9 \mathrm{Cr}-1 \mathrm{Mo}-\mathrm{V})\end{array}$ & $\mathrm{T}<371{ }^{\circ} \mathrm{C}$ & $371<\mathrm{T}<590^{\circ} \mathrm{C}$ & & $510^{\circ} \mathrm{C}^{\mathrm{b}}$ \\
\hline $\mathrm{T}_{\text {out }}=900^{\circ} \mathrm{C}$ & & $388^{\circ} \mathrm{C}^{\mathrm{a}}$ & & $517^{\circ} \mathrm{C}^{\mathrm{b}}$ \\
\hline $\mathrm{T}_{\text {out }}=950{ }^{\circ} \mathrm{C}$ & & $421{ }^{\circ} \mathrm{C}^{\mathrm{a}}$ & & \\
\hline & & & & \\
\hline Pebble bed: & & & $371<\mathrm{T}<427{ }^{\circ} \mathrm{C}$ & $427<\mathrm{T}<5388^{\circ} \mathrm{C}$ \\
\hline SA-508 & $\mathrm{T}<371^{\circ} \mathrm{C}$ & & & $450 / 463{ }^{\circ} \mathrm{C}^{\mathrm{b}, \mathrm{c}}$ \\
\hline $\mathrm{T}_{\text {out }}=900{ }^{\circ} \mathrm{C}$ & $374 / 342^{\circ} \mathrm{C}^{\mathrm{a}, \mathrm{c}}$ & & & $452 / 465{ }^{\circ} \mathrm{C}^{\mathrm{b}, \mathrm{c}}$ \\
\hline $\mathrm{T}_{\text {out }}=950^{\circ} \mathrm{C}$ & $392 / 355^{\circ} \mathrm{C}^{\mathrm{a}, \mathrm{c}}$ & & & \\
\hline & & & & \\
\hline
\end{tabular}

a. Calculated maximum wall-averaged temperature during normal operation.

b. Calculated maximum wall-averaged temperature during the depressurized conduction cooldown accident.

c. Calculated with PEBBED-THERMIX / RELAP5-3D, respectively. 


\section{CONTENTS}

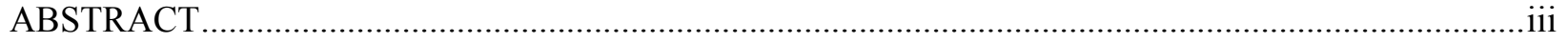

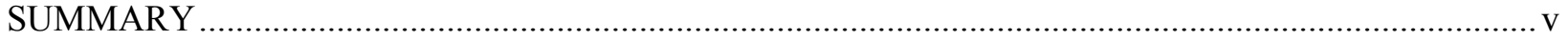

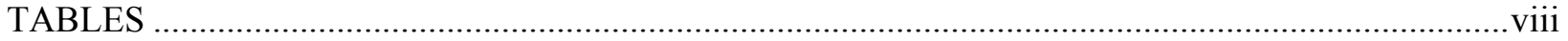

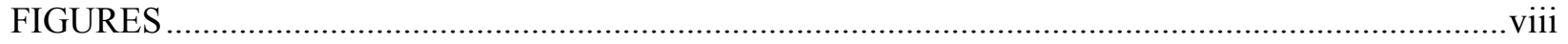

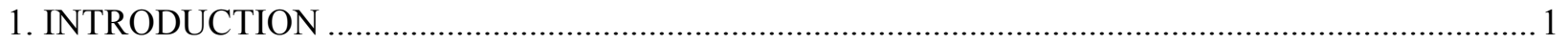

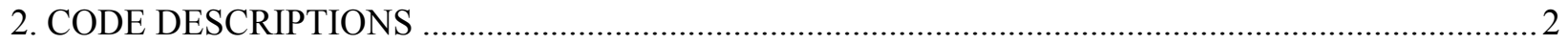

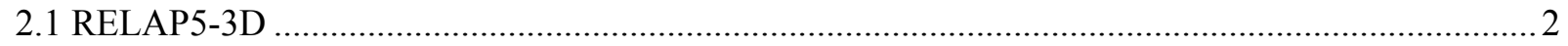

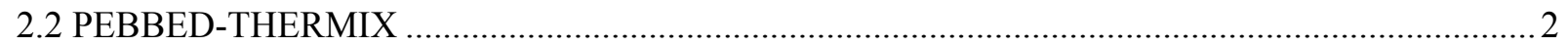

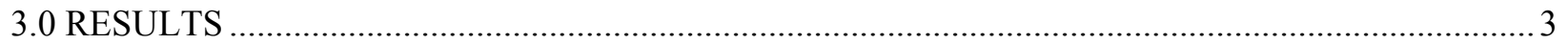

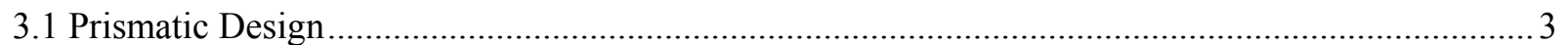

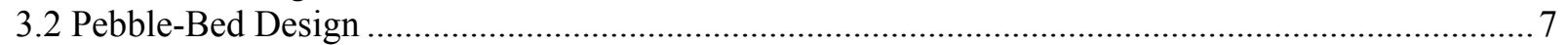

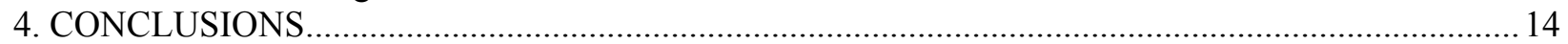

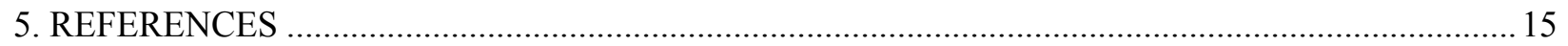




\section{TABLES}

I. A comparison of temperature limits and maximum calculated reactor vessel temperatures ... vi

1. Temperature limits for SA-508 and SA-336 steels …......................................................... 1

2. Calculated thermal-hydraulic conditions during normal operation for the prismatic VHTR ...5

3. Maximum temperatures during the depressurized conduction cooldown accident in the

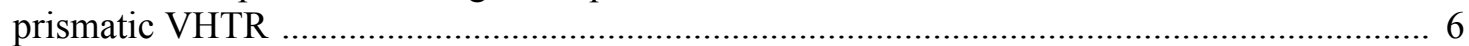

4. Dimensions of $600 \mathrm{MW}$ pebble-bed VHTR obtained using a genetic algorithm search........... 8

5. RELAP5-3D and THERMIX calculated thermal-hydraulic conditions during normal operation for the pebble-bed VHTR

6. Maximum temperatures during the depressurized conduction cooldown accident for the pebble-bed VHTR

\section{FIGURES}

1. RELAP5-3D model of the prismatic VHTR reactor vessel (from Reza et al. 2006) 4

2. Maximum reactor vessel temperatures during a depressurized conduction cooldown accident with the prismatic design 6

3. A comparison of RCCS heat removal and core decay power during a depressurized conduction cooldown accident with the prismatic design

4. Reactor vessel axial temperature profile for the prismatic design with an outlet fluid temperature of $950^{\circ} \mathrm{C}$

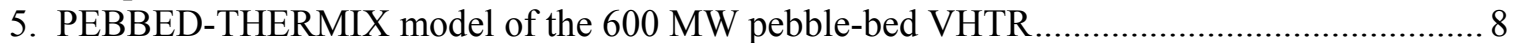

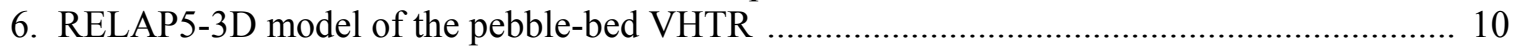

7. Reactor pressure vessel inner wall temperature profile during a depressurized conduction cooldown accident $\left(950^{\circ} \mathrm{C}\right.$ outlet fluid temperature.) ....

8. RELAP5-3D calculated maximum reactor vessel temperatures during a depressurized conduction cooldown accident with the pebble-bed design

9. A comparison of RELAP5-3D calculated RCCS heat removal and core decay power during a depressurized conduction cooldown accident with the pebble-bed design

10. Reactor vessel axial temperature profiles for the pebble-bed design with an outlet fluid temperature of $950^{\circ} \mathrm{C}$ 


\section{INTRODUCTION}

The expected high operating temperatures of the Very High Temperature Reactor (VHTR) place significant constraints on the choice of reactor pressure vessel materials. The reactor design determines the maximum operating temperature of the reactor vessel. The maximum operating temperature then determines the vessel materials that will allow an acceptable lifetime. Some designs, such as the South African Pebble Bed Modular Reactor (PBMR), propose using SA-508 steel for the reactor vessel. SA508 has been used for reactor vessels in light water reactors and requires a relatively low operating temperature. The South Africans report a normal operating temperature of $280^{\circ} \mathrm{C}$ for the PBMR reactor vessel. This low temperature is achieved with a pressure vessel conditioning system that uses an independent coolant stream to keep the reactor pressure vessel at an acceptable temperature. This is not designed as a safety system and thus is assumed to fail during a depressurized conduction cooldown. Other designs, such as the Gas-Turbine Modular Helium Reactor (GT-MHR) (General Atomics 1996) proposed operating at a higher vessel temperature of $485^{\circ} \mathrm{C}$ that requires using SA-336 $(9 \mathrm{Cr}-1 \mathrm{Mo}-\mathrm{V})$ steel.

Analyses were performed to determine maximum temperatures in the reactor pressure vessel of two potential VHTR designs during normal operation and during a depressurized conduction cooldown accident. The purpose of the analyses was to aid in the determination of appropriate reactor vessel materials for the VHTR. The designs evaluated utilized both prismatic and pebble-bed cores. The prismatic design was based on the 600-MW (thermal) GT-MHR. The pebble-bed design was based on the 400-MW PBMR, but the power was increased to $600 \mathrm{MW}$, the desired power level of the VHTR. Calculations were performed at vessel outlet fluid temperatures of 900 and $950{ }^{\circ} \mathrm{C}$.

The analyses of the prismatic design were performed using the RELAP5-3D computer code (RELAP5-3D Code Development Team 2005). The analyses of the pebble-bed design were performed with the PEBBED-THERMIX computer code (Gougar et al. 2005). Because PEBBED-THERMIX has not been extensively validated, confirmatory calculations were also performed with RELAP5-3D for the pebblebed design. These thermal-hydraulic calculations were performed with best-estimate, rather than conservative assumptions. Thus, the calculations were not intentionally biased to provide higher than expected estimates of the maximum vessel temperatures for licensing purposes.

Preliminary temperature limits for SA-508 and SA-336 steels based on the current boiler and pressure vessel code from the American Society of Mechanical Engineers (ASME) (ASME 2001, ASME 2004) are presented in Table 1. These limits are considered preliminary because they do not account for reductions due to welds and operating history. The limits presented in Table 1 are compared with the calculated results obtained from this analysis to determine initial estimates of the suitability of the different materials for the proposed designs. The limits for normal operation are based on the values given in the second column of Table 1 for SA-508 and the third column for SA-336. The limits for the depressurized conduction cooldown accident are given in the fifth column. Although the code allows operation of SA-336 up to $590{ }^{\circ} \mathrm{C}$ for $3 \times 10^{5} \mathrm{~h}$, it is expected that the vessel temperature will eventually be limited to less than $425^{\circ} \mathrm{C}$ during normal operation to avoid issues associated with creep.

Table 1. Temperature limits for SA-508 and SA-336 steels.

\begin{tabular}{|l|c|c|c|c|}
\hline Steel & \multicolumn{3}{|c|}{ Operation } \\
\hline & Unlimited & $<3 \times 10^{5} \mathrm{~h}$ & $<3000 \mathrm{~h}$ & $<1000 \mathrm{~h}$ \\
\hline SA-508 & $\mathrm{T}<371^{\circ} \mathrm{C}$ & & $371<\mathrm{T}<427^{\circ} \mathrm{C}$ & $427<\mathrm{T}<538^{\circ} \mathrm{C}$ \\
\hline SA-336 & $\mathrm{T}<371^{\circ} \mathrm{C}$ & $371<\mathrm{T}<590^{\circ} \mathrm{C}$ & & $590<\mathrm{T}<650^{\circ} \mathrm{C}$ \\
\hline
\end{tabular}


The RELAP5-3D and PEBBED-THERMIX computer codes are described in Section 2. Results of the thermal-hydraulic analyses of the prismatic and pebble-bed designs are presented in Section 3. Conclusions are presented in Section 4. References are presented in Section 5.

\section{CODE DESCRIPTIONS}

Brief descriptions of the RELAP5-3D and PEBBED-THERMIX computer codes are presented in Sections 2.1 and 2.2, respectively.

\subsection{RELAP5-3D}

RELAP5-3D (RELAP5-3D Code Development Team 2005) was developed for the thermal-hydraulic analysis of light water reactors and related experimental systems during loss-of-coolant accidents and operational transients. The code originally contained a one-dimensional, nonhomogeneous, and nonequilbirum model for two-phase flow and a point model for reactor kinetics. The code currently contains multi-dimensional models for flow and reactor kinetics, but one-dimensional models were used in this analysis.

RELAP5-3D has the capability to simulate a wide variety of nuclear systems and working fluids. The code currently simulates over twenty working fluids, including light and heavy water, helium, carbon dioxide, hydrogen, nitrogen, helium-xenon, lead-bismuth, sodium, lithium, potassium, sodium-potassium, ammonia, and several liquid salts.

Recent assessments of RELAP5-3D that are applicable to the VHTR are described by Oh et al. (2006).

A special version of the RELAP5-3D was created for the pebble-bed analysis described in Section 3.2. The special code version implemented correlations for heat transfer and wall friction coefficients applicable for pebble-bed reactors based on correlations given by Fenech (1981).

\subsection{PEBBED-THERMIX}

PEBBED is a three-dimensional core simulator code developed at the Idaho National Laboratory specifically for pebble-bed reactor design and analysis (Gougar et al. 2004). It converges directly upon the asymptotic or equilibrium fuel cycle using an integrated neutron diffusion-depletion solver. Core design optimization is performed using a genetic algorithm operating on core geometry and pebble flow parameters. Core temperature profiles can be obtained using a one-dimensional embedded thermalhydraulic solver or with a coupled THERMIX calculation. THERMIX is a two-dimensional (RZ) heat transfer and gas dynamics code developed for the German pebble-bed reactor program. It is part of the VSOP PBR fuel cycle analysis system (Teuchert 1994) but the THERMIX module has been extracted recently for use with other codes. THERMIX contains material properties and correlations validated for PBR analysis under the German High Temperature Reactor program. The PBMR Corporation uses a modified version of VSOP (with THERMIX) for their reactor design and fuel cycle analyses.

Burnup and temperature feedback are treated by iterating between PEBBED-THERMIX and COMBINE, the INL spectrum code (Yoon 1994). 


\subsection{RESULTS}

Results of the thermal-hydraulic analyses of the prismatic and pebble-bed versions of the VHTR are presented in Sections 3.1 and 3.2, respectively.

\subsection{Prismatic Design}

The evaluation of the VHTR containing prismatic blocks is based on the design of the GT-MHR (General Atomics 1996). The GT-MHR was designed to operate at core inlet and outlet temperatures of 491/850 ${ }^{\circ} \mathrm{C}$. The inside wall temperature of the reactor vessel was $485^{\circ} \mathrm{C}$, which was just slightly below the core inlet fluid temperature. The reactor vessel was fabricated from $9 \mathrm{Cr}-1 \mathrm{Mo}-\mathrm{V}$ ferritic steel. The vessel design limits used by General Atomics were $495^{\circ} \mathrm{C}$ for $4.6 \times 10^{5} \mathrm{~h}$ (normal operation) and $538^{\circ} \mathrm{C}$ for 1.0 $\mathrm{x} 10^{3} \mathrm{~h}$ (transient conditions). General Atomics reported a maximum reactor vessel (midwall) temperature of $490{ }^{\circ} \mathrm{C}$ versus an accident limit of $565^{\circ} \mathrm{C}$ during a depressurized conduction cooldown accident. Note that the temperature limits used by General Atomics predated the ASME code for 9Cr$1 \mathrm{Mo}-\mathrm{V}$ steel and were about $100{ }^{\circ} \mathrm{C}$ lower than the values given in Table 1.

The VHTR is desired to operate at a higher outlet temperature than the GT-MHR to increase the efficiency of the electrical production cycle and/or to allow for efficient production of hydrogen. Although the VHTR has not yet been designed, current goals call for outlet temperatures in the range of 900 to $950{ }^{\circ} \mathrm{C}$. Raising the GT-MHR inlet and outlet temperatures by 50 to $100{ }^{\circ} \mathrm{C}$ would achieve the desired temperature goal for efficiency, but would also increase the maximum reactor vessel temperature. Maintaining the inlet temperature at the GT-MHR value and reducing the core flow to achieve the desired outlet temperature would keep the vessel temperature relatively low but would cause concerns about flow starvation in the hot channels of the core.

Reza et al. (2006) evaluated design modifications to the GT-MHR that routed the inlet flow through holes in the outer reflector rather than through channels between the core barrel and the reactor vessel. This design prevented the inlet flow from contacting the reactor vessel, which enabled the inlet and outlet fluid temperatures to be increased while lowering the operating temperature of the reactor vessel. Detailed simulations of the vessel lower head were not performed, but it was assumed that the lower head could be isolated from the inlet flow, such as by applying insulation or by using a distribution header to supply the flow holes in the outer reflector.

This evaluation utilized the GT-MHR design as modified by Reza et al. (2006). RELAP5-3D (RELAP53D Code Development Team 2005) calculations were performed to determine the reactor vessel temperature during normal operation and a depressurized conduction cooldown accident. The RELAP53D input model was based on the model of Reza et al. (2006), which in turn was based on the model developed for the Next Generation Nuclear Plant by MacDonald et al. (2003). The model of Reza et al. (2006) was modified to produce the desired core inlet/outlet temperature conditions for this evaluation.

The RELAP5-3D model of the VHTR vessel is shown in Figure 1. The active core (Components 152 through 156) was modeled with three radial rings, corresponding to the three annular rings of prismatic fuel blocks in the design, and ten axial levels. The upper and lower reflectors were each modeled with a single axial level. Core bypass paths were simulated through the inner and outer reflectors (Components 142 and 145, respectively). In the original model developed by MacDonald et al. (2003), cold helium from the vessel inlet flowed upwards through an annular riser (Component 130) and into the core inlet plenum (Component 140). In the revised model developed by Reza et al. (2006), the riser was modeled as a region of stagnant helium and the cold helium flowed upwards through flow holes in the outer 
reflector (Component 132). Conduction enclosure models were used to simulate the heat transfer between the three core rings and between the core and the reflectors. Radiation enclosure models were used to simulate the heat transfer across the riser and between the reactor vessel and the containment wall. The outer surface of the containment wall was cooled by the reactor cavity cooling system (RCCS). Naturally-circulating air was the ultimate heat sink for the RCCS.

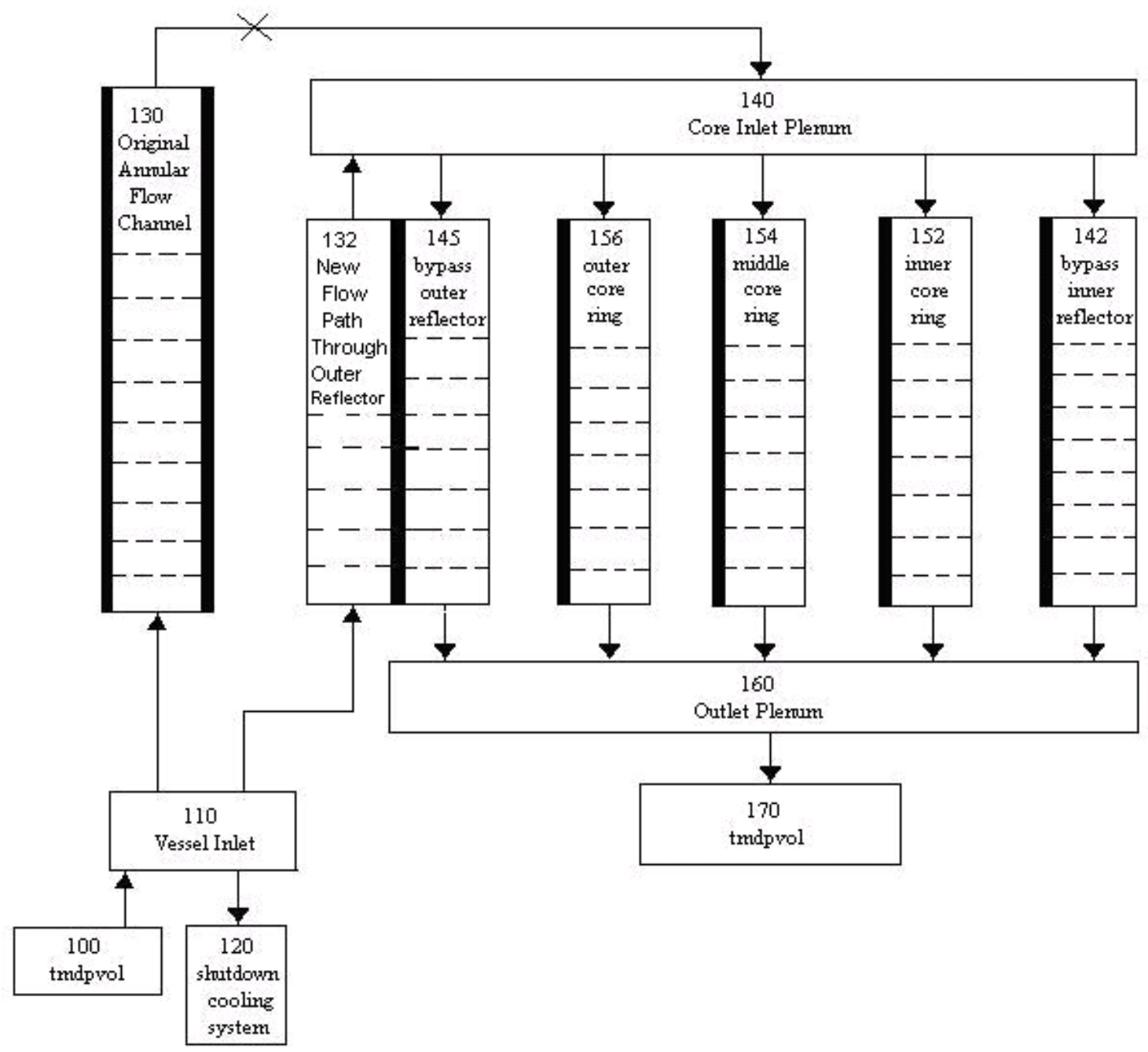

Figure 1. RELAP5-3D model of the prismatic VHTR reactor vessel (from Reza et al. 2006).

Steady-state calculations were performed with vessel outlet fluid temperatures of 900 and $950{ }^{\circ} \mathrm{C}$. Results are presented in Table 2. The table contains two vessel temperatures, one at the inner wall and the other at the radial center of the inner and outer walls. Both maximum temperatures generally occurred at the same axial location in the vessel. The midwall temperature is appropriate for comparison with the temperature limits given in Table 1 because the ASME code (2004) specifies the use of the wall-averaged temperature. The higher temperature at the inner wall is an indication of the heat conduction through the wall and the subsequent heat transfer to the RCCS. 
Table 2. Calculated thermal-hydraulic conditions during normal operation for the prismatic VHTR.

\begin{tabular}{|l|c|c|}
\hline Parameter & $\mathrm{T}_{\text {out }}=900{ }^{\circ} \mathrm{C}$ & $\mathrm{T}_{\text {out }}=950{ }^{\circ} \mathrm{C}$ \\
\hline Power, $\mathrm{MW}$ & & 600 \\
\hline Pressure, $\mathrm{MPa}$ & 600 & 7.00 \\
\hline Differential pressure, $\mathrm{MPa}$ & 7.00 & 0.0802 \\
\hline Inlet temperature, ${ }^{\circ} \mathrm{C}$ & 0.0764 & 590 \\
\hline Outlet temperature, ${ }^{\circ} \mathrm{C}$ & 540 & 950 \\
\hline Flow rate, kg/s & 900 & 325.1 \\
\hline Core bypass, $\%$ & 325.0 & 9.53 \\
\hline Maximum vessel temperature (inner wall), ${ }^{\circ} \mathrm{C}$ & 9.59 & 447 \\
\hline Maximum vessel temperature (midwall), ${ }^{\circ} \mathrm{C}$ & 410 & 421 \\
\hline Maximum fuel temperature, ${ }^{\circ} \mathrm{C}$ & 388 & 1112 \\
\hline RCCS power, $\mathrm{MW}$ & 1064 & 2.13 \\
\hline
\end{tabular}

The steady-state reactor vessel temperature was far less than the limit of $590{ }^{\circ} \mathrm{C}$ for normal operation with SA-336 steel given in Table 1. The calculated results are expected to be reasonably accurate because the original RELAP5-3D model developed by MacDonald et al. (2003) was benchmarked against results calculated by General Atomics for the GT-MHR. The benchmarking showed that the maximum reactor vessel temperatures predicted by RELAP5-3D during normal operation and during the depressurized conduction cooldown accident were within 5 and $13{ }^{\circ} \mathrm{C}$, respectively, of the values reported by General Atomics.

The calculated response of the maximum midwall temperature of the reactor vessel during a depressurized conduction cooldown accident is shown in Figure 2. During normal operation, heat transfer due to convection to the fluid in the gaps between reflector blocks and the coolant channels in the outer reflector was much greater than the heat transfer due to conduction through the reflector. Conduction became the dominant heat transfer mechanism after the scram and the depressurization. The temperatures of the core barrel and the reactor vessel initially decreased during the accident due to the decrease in convective heat transfer combined with the long thermal response time of the outer reflector. Eventually the temperature gradients due to conduction worked their way through the outer reflector and the vessel temperature increased because of the mismatch between the core decay power and the heat removed by the RCCS (see Figure 3). The reactor vessel temperature peaked near the time when the power removed by the RCCS exceeded the decay heat. 


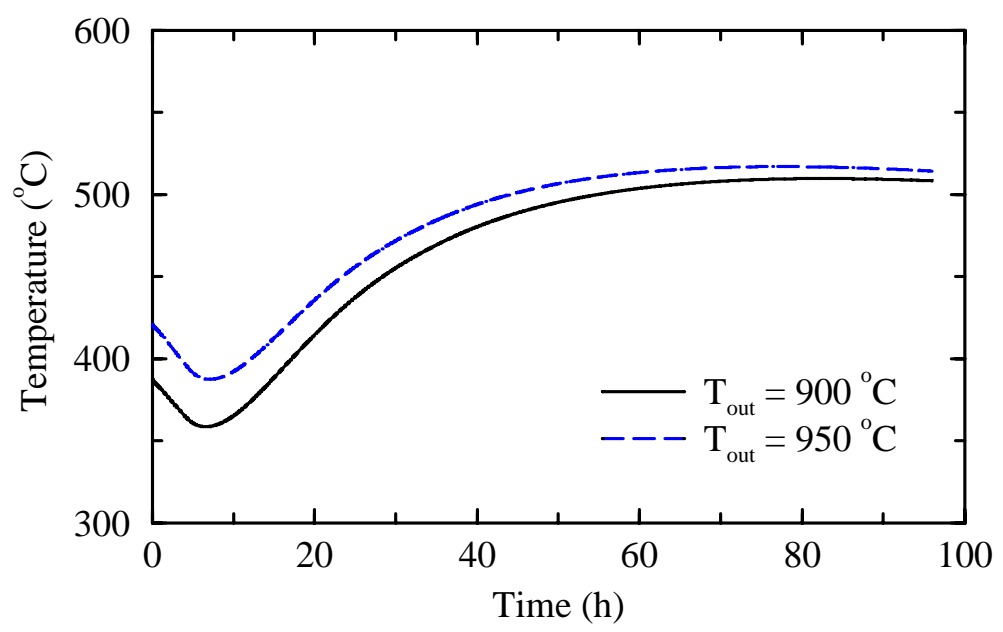

Figure 2. Maximum reactor vessel temperatures during a depressurized conduction cooldown accident with the prismatic design.

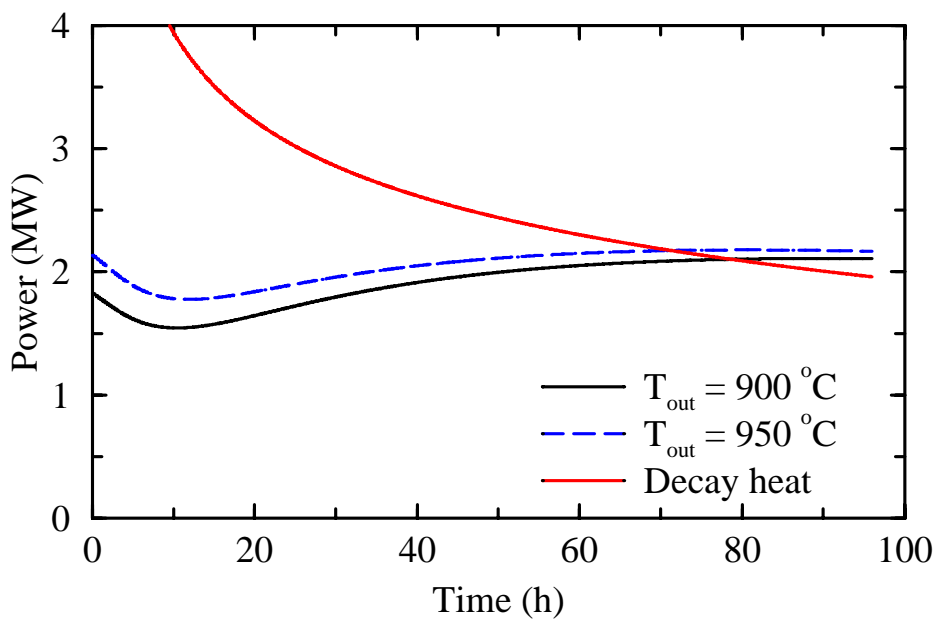

Figure 3. A comparison of RCCS heat removal and core decay power during a depressurized conduction cooldown accident with the prismatic design.

Table 3 presents maximum calculated temperatures during the conduction cooldown event. The maximum predicted midwall temperatures remained well below the accident limit of $650{ }^{\circ} \mathrm{C}$ given in Table 1. A comparison of Tables 2 and 3 reveals that a $50{ }^{\circ} \mathrm{C}$ increase in outlet temperature caused the maximum midwall temperature to increase by $33^{\circ} \mathrm{C}$ at steady state, but by only $7^{\circ} \mathrm{C}$ during the accident.

Table 3. Maximum temperatures during the depressurized conduction cooldown accident in the prismatic VHTR.

\begin{tabular}{|l|c|c|}
\hline Parameter & $\mathrm{T}_{\text {out }}=900{ }^{\circ} \mathrm{C}$ & $\mathrm{T}_{\text {out }}=950{ }^{\circ} \mathrm{C}$ \\
\hline Maximum vessel temperature (inner wall), ${ }^{\circ} \mathrm{C}$ & 553 & 562 \\
\hline Maximum vessel temperature (midwall), ${ }^{\circ} \mathrm{C}$ & 510 & 517 \\
\hline Maximum fuel temperature, ${ }^{\circ} \mathrm{C}$ & 1501 & 1526 \\
\hline
\end{tabular}


Figure 4 shows the axial temperature profiles at the inner surface of the reactor vessel at two times, $0.0 \mathrm{~h}$ which corresponds to normal, full-power operation and $83.3 \mathrm{~h}$ which is near the time of the peak temperature during the depressurized conduction cooldown accident. The reactor vessel temperature during normal operation is nearly independent of elevation in the region between the bottom of the active fuel (BAF) and the top of the active fuel (TAF). The wall temperature decreased above the active fuel because of the presence of a thermal shield. The calculated temperature below the active core decreased because the model assumed that the inlet and outlet fluids did not contact the vessel and that the only source of heat transfer to the lower head was due to radiation from adjacent heat structures. A more detailed evaluation of this potentially limiting region will be required once the design is completed.

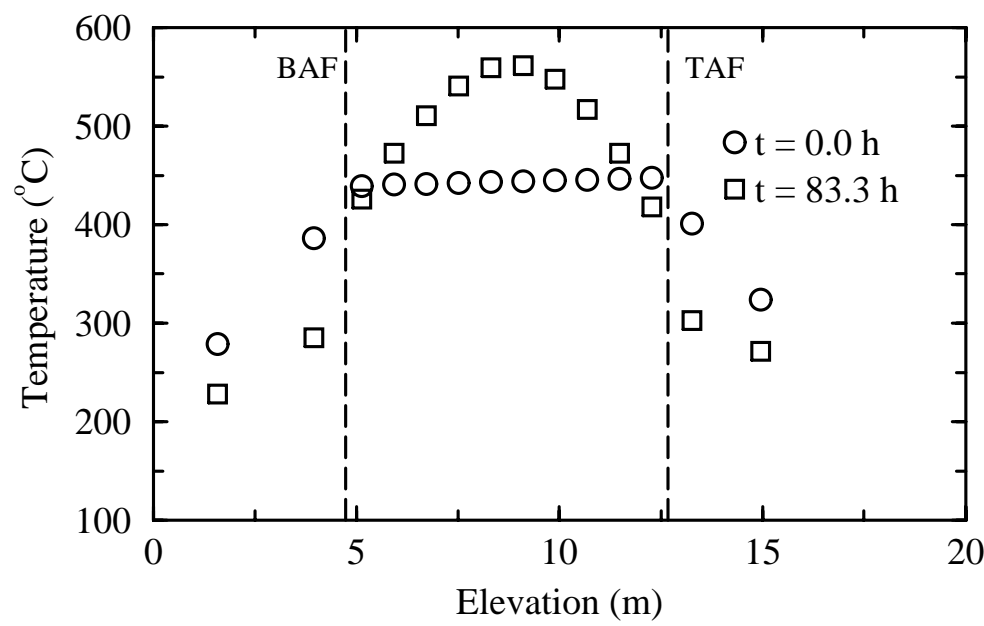

Figure 4. Reactor vessel axial temperature profile for the prismatic design with an outlet fluid temperature of $950{ }^{\circ} \mathrm{C}$.

The axial temperature profile shifted significantly during the depressurized conduction cooldown accident. At the time of the peak temperature, the maximum vessel temperature occurred near the axial center of the core, which was the peak power location in this analysis.

\subsection{Pebble-Bed Design}

The evaluation of the pebble-bed VHTR was based on PEBBED-THERMIX and RELAP5-3D models developed specifically for this task.

The PBMR has a rated thermal power of $400 \mathrm{MW}$ and thus its basic design had to be modified to accommodate the higher power of the VHTR. A genetic algorithm was employed to automatically search for a core geometry that would yield a vessel comparable in size to other $600 \mathrm{MW}$ high temperature reactor designs and achieve passive safety, i.e. the fuel temperature will remain under $1600^{\circ} \mathrm{C}$ during a depressurized conduction cooldown accident. Using the PBMR-400 design as a starting point, various perturbations to the core and reflector dimensions were explored and analyzed using PEBBEDTHERMIX. Once a promising candidate was identified, final iterations with COMBINE were executed to generate a self-consistent physical model. PEBBED was also used to design a $600 \mathrm{MW}$ pebble-bed VHTR in a previous study (MacDonald et al. 2003) but without detailed THERMIX analysis and temperature feedback in the cross sections. The reactor obtained in this current work is thus a more realistic model. The basic reactor dimensions are shown in Table 4. 
Table 4. Dimensions of 600 MW pebble-bed VHTR obtained using a genetic algorithm search.

\begin{tabular}{|l|c|}
\hline Dimension & Value $(\mathrm{m})$ \\
\hline Height of active core & 10.96 \\
\hline Radius of inner reflector & 1.582 \\
\hline Outer radius of fuel annulus & 2.464 \\
\hline Outer radius of outer reflector & 3.072 \\
\hline
\end{tabular}

The thicknesses of the top and bottom axial reflectors $(1.86 \mathrm{~m}$ and $4.36 \mathrm{~m})$ were not changed from the values used in the PBMR-400 Coupled-Code Benchmark model (OECD 2005). Control rods (B4C) were assumed to be partially inserted into the outer reflector to allow for xenon override. A complete description of the THERMIX model is shown in Figure 5.

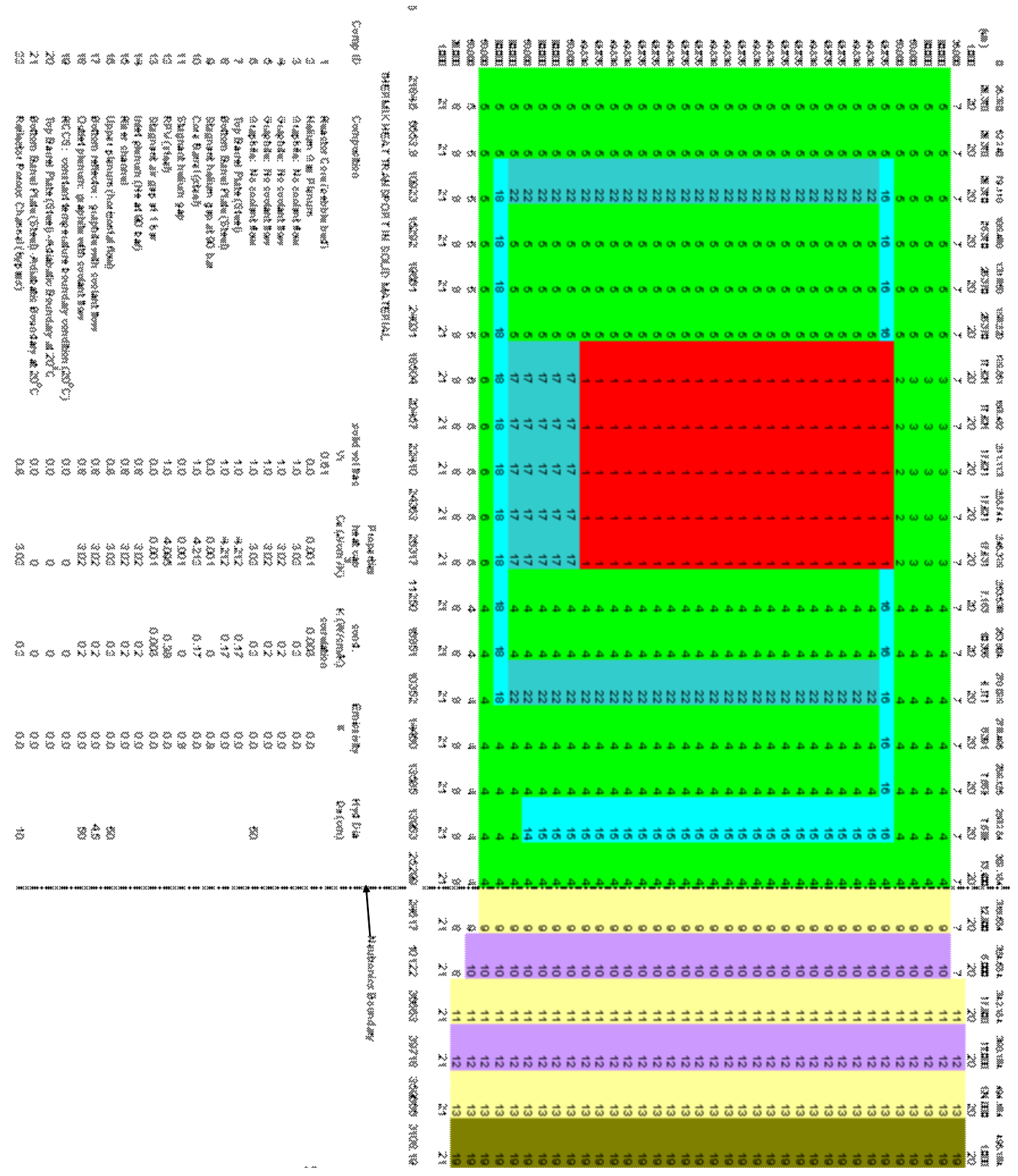

Figure 5: PEBBED-THERMIX model of the 600 MW pebble-bed VHTR. 
The active core is represented by composition 1 . The cold He inlet is composition 14 and the coolant ascends through a riser (composition 15). It then passes through the upper plenum (composition 16), through the core and porous bottom reflector (composition 17) and out through the lower plenum (composition 18). Parts of the inner and outer radial reflectors are treated as porous to allow for bypass flow (composition 22). The pressure drops across these channels were adjusted to yield an overall bypass flow of $10 \%$.

The upper and lower boundaries (compositions 20 and 21) are fixed as adiabatic so that heat transfer out of the vessel is through the radial boundary. This boundary is set at a constant temperature of $20^{\circ} \mathrm{C}$ to simulate a working RCCS. The reactor pressure vessel is represented by composition 12 .

The corresponding RELAP5-3D input model is shown in Figure 6. The heat source term was obtained from the PEBBED calculation and assumed that all fission power was deposited locally. The primary components are the riser (Component 120), gas plenum (Component 140), core (Components 151 through 155), and the outlet plenum (Component 180). The active core was modeled with five radial rings and eleven axial levels. Core bypass paths were simulated through the inner and outer reflectors (Components 142 and 145, respectively). The flow areas of these paths were adjusted to achieve a total bypass flow near $10 \%$. The stagnant helium gaps between the outer reflector and the core barrel and the core barrel and the reactor vessel were modeled with Components 182 and 184. Conduction enclosure models were used to simulate the heat transfer between the various core rings and between the core and the reflectors. Radiation enclosure models were used to simulate the heat transfer across the stagnant gaps and between the reactor vessel and the containment wall. As with the THERMIX model, the outer surface of the containment wall was held at $20^{\circ} \mathrm{C}$, simulating a water-cooled RCCS. The outer surfaces of the top and bottom barrel plates, which are located above the gas plenum and below the outlet plenum, respectively, were modeled adiabatically. 


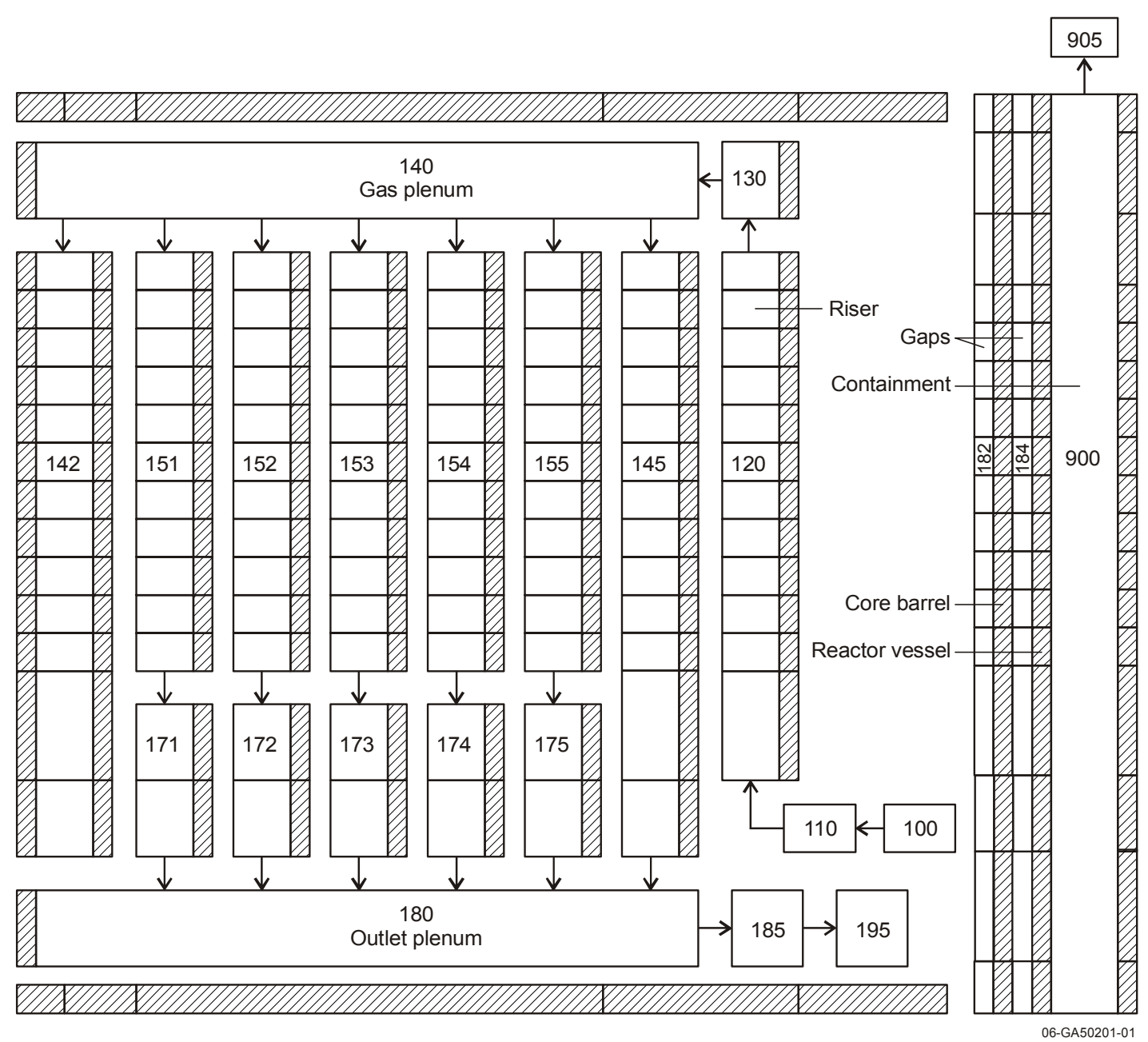

Figure 6. RELAP5-3D model of the pebble-bed VHTR.

Steady-state calculations were performed with outlet temperatures of 900 and $950{ }^{\circ} \mathrm{C}$. Results are presented in Table 5.

Table 5. RELAP5-3D and THERMIX calculated thermal-hydraulic conditions during normal operation for the pebble-bed VHTR.

\begin{tabular}{|l|c|c|c|c|}
\hline Parameter & \multicolumn{2}{|c|}{$\mathrm{T}_{\text {out }}=90{ }^{\circ} \mathrm{C}$} & \multicolumn{2}{c|}{$\mathrm{T}_{\text {out }}=950{ }^{\circ} \mathrm{C}$} \\
\hline & RELAP5-3D & THERMIX & RELAP5-3D & THERMIX \\
\hline Power, MW & 600 & 600 & 600 & 600 \\
\hline Pressure, MPa & 9.00 & 9.00 & 9.00 & 9.00 \\
\hline Differential pressure, $\mathrm{MPa}$ & 0.290 & 0.216 & 0.238 & 0.181 \\
\hline Inlet temperature, ${ }^{\circ} \mathrm{C}$ & 482 & 482 & 482 & 482 \\
\hline Outlet temperature, ${ }^{\circ} \mathrm{C}$ & 900 & 899 & 950 & 948 \\
\hline Flow rate, $\mathrm{kg} / \mathrm{s}$ & 275 & 276 & 246 & 247 \\
\hline Core bypass, \% & 9.8 & 10.1 & 10.0 & 9.9 \\
\hline Maximum vessel temperature (inner wall), ${ }^{\circ} \mathrm{C}$ & 354 & 396 & 368 & 410 \\
\hline Maximum vessel temperature (midwall), ${ }^{\circ} \mathrm{C}$ & 342 & 374 & 356 & 393 \\
\hline Maximum fuel temperature, ${ }^{\circ} \mathrm{C}$ & 1072 & 1043 & 1141 & 1096 \\
\hline RCCS power, $\mathrm{MW}$ & 1.43 & & 1.46 & \\
\hline
\end{tabular}


The steady states calculated with both codes were generally in reasonable agreement. However, the calculations of maximum vessel wall temperature were about $40{ }^{\circ} \mathrm{C}$ higher with THERMIX. The differential pressure drop across the vessel was about 30\% larger with RELAP5-3D, with the difference primarily occurring in the riser component. The maximum fuel temperatures were also somewhat higher with RELAP5-3D, probably because it explicitly accounted for the temperature rise between the surface and the center of a representative pebble in each core ring.

Several differences were noted between the steady states obtained for the pebble bed and those obtained previously with the prismatic core. First, the assumed inlet fluid temperature was lower with the pebble bed, which resulted in a larger temperature rise across the vessel and a lower mass flow rate. Second, even though the mass flow was reduced, the pressure drop across the vessel was larger because of the increased friction associated with the porous media compared to the open flow channels in the prismatic design. Third, the maximum vessel temperature was about $80^{\circ} \mathrm{C}$ lower with the pebble bed, primarily because of the reduced sink temperature associated with the water-cooled RCCS versus the air-cooled design used with the prismatic core. Finally, the maximum fuel temperature in the pebble bed was about $30{ }^{\circ} \mathrm{C}$ higher than in the prismatic design. This result was unexpected because of the increased heat transfer coefficient from the pebbles compared to that from the coolant channels in the prismatic design. The cause of the higher fuel temperature was an increased maximum radial power peaking factor, 1.20 from the PEBBED-THERMIX calculations versus 1.12 from the power profile assumed by MacDonald et al. (2003) for the prismatic core.

The response of the pebble-bed VHTR as calculated by RELAP5-3D and THERMIX during a depressurized conduction cooldown accident is shown in the next several figures. Figure 7 shows the THERMIX-computed axial temperature profile at the inner surface of the reactor vessel at various times during the accident. As was observed with the prismatic core, the maximum temperature initially decreased following the reactor scram and the decrease in convective heat transfer following the depressurization (see Figure 8). The maximum vessel temperature eventually increased because of the mismatch between the core decay power and the heat removed by the RCCS (see Figure 9). The sharp change in slope near ten hours occurred as the location of the maximum temperature switched from near the bottom of the vessel to near the axial center of the core. The maximum temperature occurred about 80 $\mathrm{h}$ after the start of the accident and remained far below the accident limit of $538^{\circ} \mathrm{C}$ for SA-508 steel. 


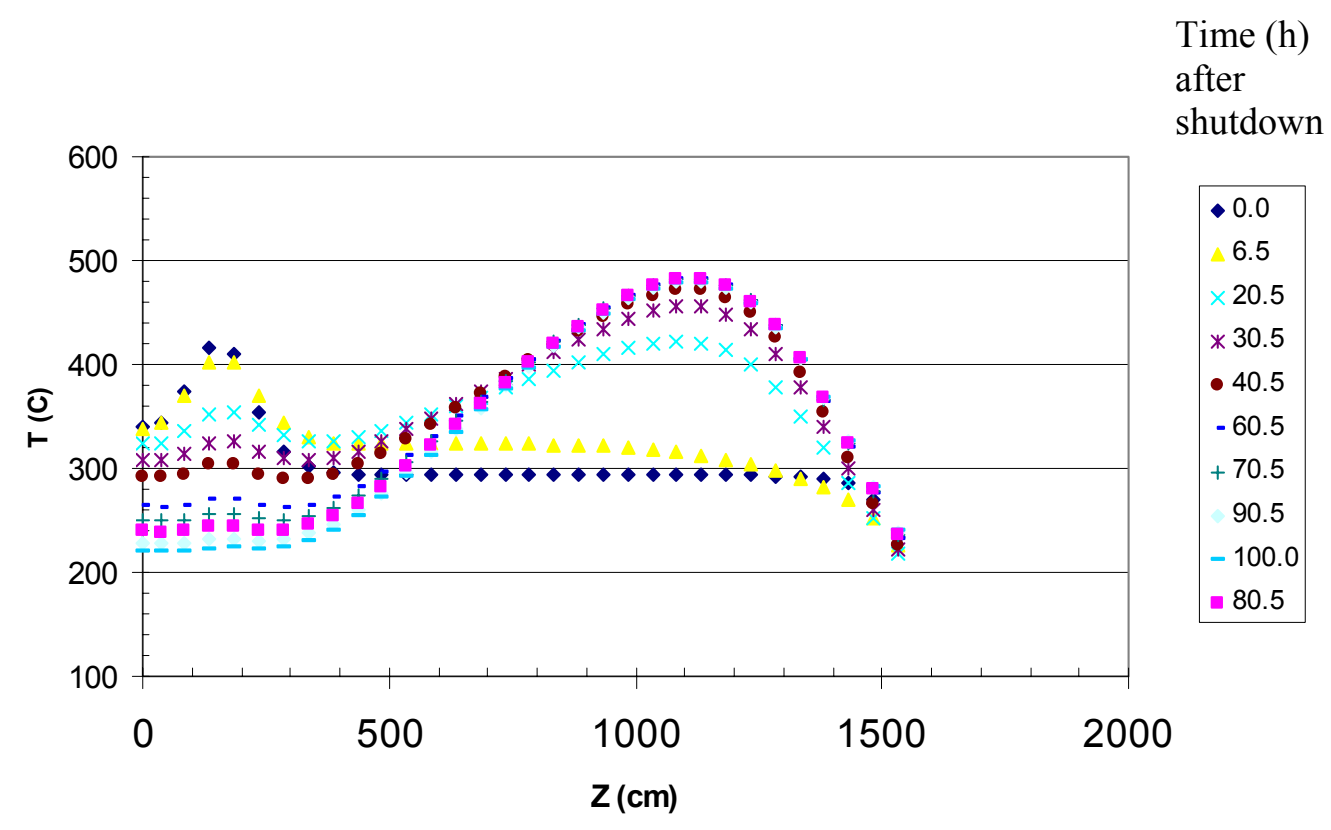

Figure 7. Reactor pressure vessel inner wall temperature profile during a depressurized conduction cooldown accident $\left(950^{\circ} \mathrm{C}\right.$ outlet fluid temperature).

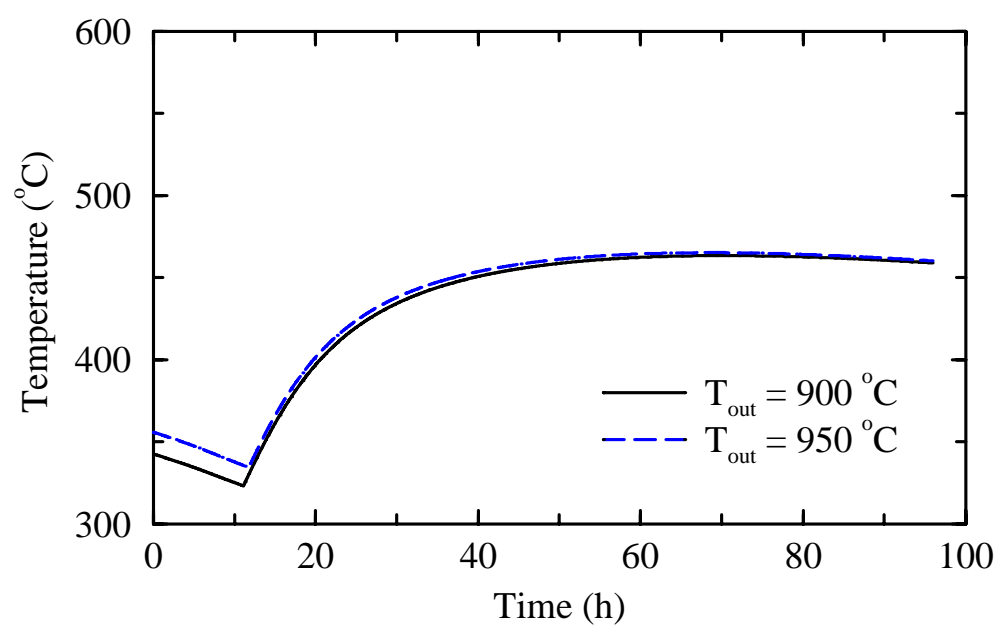

Figure 8. RELAP5-3D calculated maximum reactor vessel midwall temperatures during a depressurized conduction cooldown accident with the pebble-bed design. 


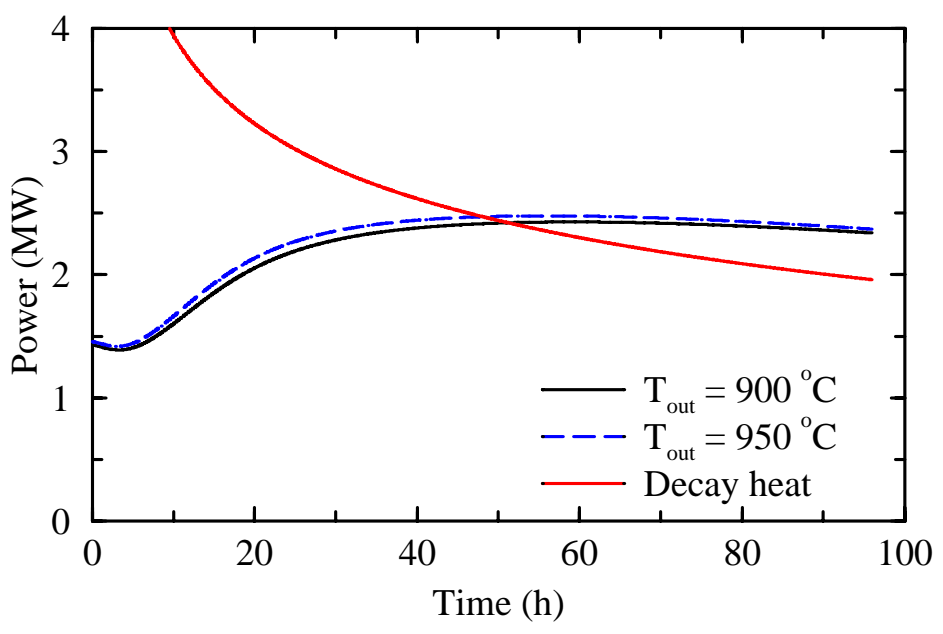

Figure 9. A comparison of RELAP5-3D calculated RCCS heat removal and core decay power during a depressurized conduction cooldown accident with the pebble-bed design.

Figure 10 shows axial temperature profiles at the inner surface of the reactor vessel at 0.0 and $83.3 \mathrm{~h}$ after the start of the accident. RELAP5-3D results are shown with symbols while the THERMIX results are shown with solid lines. The calculated temperature profiles were similar with both codes. At steady state, the temperature between the BAF and TAF was nearly independent of the elevation. The maximum temperature occurred below the outlet plenum, which was heated by the outlet flow but not cooled by flow through the riser and bypass flow paths as occurred at higher elevations. The maximum temperature obtained from THERMIX was about $40^{\circ} \mathrm{C}$ higher than the value obtained from RELAP5-3D, perhaps because of the more detailed nodalization used in the THERMIX model. The calculated trends were similar with both codes during the conduction cooldown accident. In particular, the maximum temperature during the conduction cooldown accident occurred near the elevation of the peak power location in the core, which was slightly above the core centerline for this analysis. The maximum calculated values were within about $10^{\circ} \mathrm{C}$ during the accident.

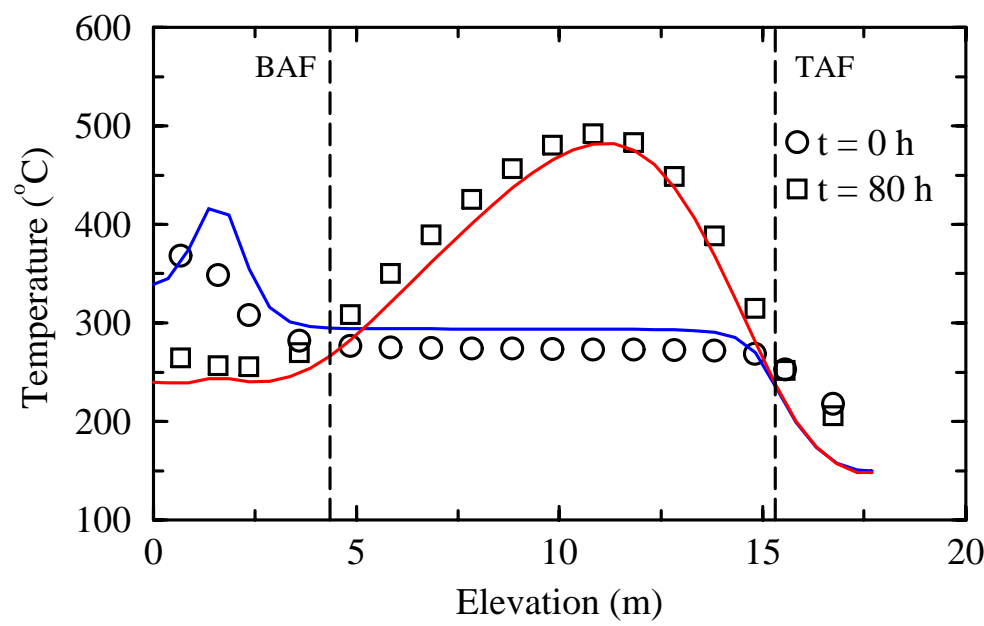

Figure 10. Reactor vessel axial temperature profiles for the pebble-bed design with an outlet fluid temperature of $950^{\circ} \mathrm{C}$. 
The maximum temperatures calculated during the conduction cooldown event are given in Table 6 . The $50{ }^{\circ} \mathrm{C}$ variation in initial outlet temperature had only a small effect on the maximum temperatures during the accident.

Table 6. Maximum temperatures during the depressurized conduction cooldown accident for the pebblebed VHTR.

\begin{tabular}{|l|c|c|c|c|}
\hline Parameter & \multicolumn{2}{|c|}{$\mathrm{T}_{\text {out }}=900{ }^{\circ} \mathrm{C}$} & \multicolumn{2}{c|}{$\mathrm{T}_{\text {out }}=950{ }^{\circ} \mathrm{C}$} \\
\hline & RELAP5-3D & THERMIX & RELAP5-3D & THERMIX \\
\hline Maximum vessel temperature (inner wall), ${ }^{\circ} \mathrm{C}$ & 492 & 480 & 494 & 482 \\
\hline Maximum vessel temperature (midwall), ${ }^{\circ} \mathrm{C}$ & 463 & 451 & 465 & 452 \\
\hline Maximum fuel temperature, ${ }^{\circ} \mathrm{C}$ & 1486 & 1550 & 1493 & 1554 \\
\hline
\end{tabular}

For the $950{ }^{\circ} \mathrm{C}$ outlet temperature case, the THERMIX calculation was allowed to run until the reactor pressure vessel temperature dropped below $371{ }^{\circ} \mathrm{C}$, about 540 hours after shutdown (the control rods were assumed fully inserted to prevent re-criticality). The pressure vessel thus can be expected to remain at an elevated temperature for about 22 days assuming no active measures are taken to cool it. According to Table 1, SA-508 steel can withstand elevated temperatures for at least 40 days.

\section{CONCLUSIONS}

Current designs for the VHTR with a prismatic core do not allow the use of SA-508 steel for the reactor vessel. Best-estimate calculations of the maximum reactor vessel temperature during normal operation exceeded the value allowed for SA-508, but were at least $170{ }^{\circ} \mathrm{C}$ below the $590{ }^{\circ} \mathrm{C}$ limit for SA-336 when the design improvements described by Reza et al. (2006) were modeled. The maximum temperature during normal operation was just slightly below the $425^{\circ} \mathrm{C}$ value where creep is expected to become an issue and further design improvements may be required to provide additional margin. Note that the design of the important lower head region has yet to be completed with the prismatic core.

For the pebble-bed design, the maximum vessel wall temperature during normal operation was $16{ }^{\circ} \mathrm{C}$ below the allowed value for unlimited operation of SA-508 based on the RELAP5-3D calculations, but was $21{ }^{\circ} \mathrm{C}$ above the allowed value based on the PEBBED-THERMIX calculations. These calculations indicate that some design changes, such as the use of active vessel cooling, are required to limit the vessel temperature during normal operation. Even though the values calculated with RELAP5-3D were lower than the temperature limit, the margin to the limit was probably inadequate based on the uncertainty in the calculation.

The maximum vessel temperatures increased significantly during a depressurized conduction cooldown accident. However, the temperatures remained at least $70^{\circ} \mathrm{C}$ below the accident limits allowed by the ASME code for $1000 \mathrm{~h}$ of operation with both designs.

The PEBBED-THERMIX calculations of the pebble-bed VHTR were generally confirmed by the RELAP5-3D calculations. During normal operation, the predicted axial profiles in reactor vessel temperature were similar with both codes, but the maximum predicted temperature was about $40{ }^{\circ} \mathrm{C}$ higher with PEBBED-THERMIX. The trends of the calculated vessel temperatures and the maximum values were similar during the depressurized conduction cooldown accident. This agreement is considered reasonable based on the expected uncertainty in either calculation. 


\section{REFERENCES}

ASME, 2001, Use of SA-533 Grade B, Class 1 Plate and SA-508 Class 3 Forgings and their Weldments for Limited Elevated Temperature Service, Section III, Division 1, Case N-499-2, September 7.

ASME, 2004, 2004 ASME Boiler \& Pressure Vessel Code, Section III, Division 1- Subsection NH, Class 1 Components in Elevated Temperature Service, July 1.

Fenech, H., 1981, Heat Transfer and Fluid Flow in Nuclear Systems, Pergamon Press, New York.

General Atomics, 1996, Gas Turbine-Modular Helium Reactor (GT-MHR) Conceptual Design Description Report, 910720, Revision 1, July.

Gougar, H. D., W. K. Terry, A. M. Ougouag, and K. N. Ivanov, 2004, "Design of Pebble-bed Reactor Using Genetic Algorithms," Proceedings of PHYSOR 2004 - The Physics of Fuel Cycles and Advanced Nuclear Systems: Global Developments, American Nuclear Society Topical Meeting, Chicago, IL, April 25-29, 2004.

Gougar, H. D. and W. K. Terry, 2005, Completion of PEBBED-THERMIX Coupling, INL/EXT-0502584, December.

MacDonald, P. E., J. W. Sterbentz, R. L. Sant, P. D. Bayless, R. R. Schultz, H. D. Gougar, R. L. Moore, A. M. Ougouag, and W. K. Terry, 2003, NGNP Preliminary Point Design-Results of the Initial Neutronics and Thermal-Hydraulic Assessments, INEEL/EXT-03-00870, Revision 1, September.

OECD, 2005, PBMR-400 Coupled Neutronics/Thermal-hydraulic Transient Benchmark, OECD-NEANSC, Draft Report.

Oh, C. H., C. Davis, L. Siefken, R. Moore, H. C. NO, J. Kim, G. C. Park, J. C. Lee, and W. R. Martin, 2006, Development of Safety Analysis Codes and Experimental Validation for a Very High Temperature Gas-Cooled Reactor, INL/EXT-06-01362, March.

Reza, S. M. M., E. A. Harvego, M. Richards, A. Shenoy, and K. L. Peddicord, 2006, "Design of Alternative Configuration of Coolant Inlet Flow for Modular High Temperature Helium Cooled Reactor," Proceedings of ICAPP '06, Reno, NV USA, June 4-8, Paper 6338.

RELAP5-3D Code Development Team, 2005, RELAP5-3D Code Manual Code Structure, System Models, and Solution Methods, INEEL-EXT-98-00834, Vol. 1, Revision 2.3, April.

Teuchert, E., K. A. Haas, J. J. Rutten, H. Brockmann, H. Gerwin, U. Ohlig, and W. Scherer, 1994, V.S.O.P. ('94) Computer Code System for Reactor Physics and Fuel Cycle Simulation Input Manual and Comments, Forschungszentrum Julich GmbH, JuL-2897, April.

Yoon, W. Y., 1994, COMBINE-6 Cycle 1, Internal Letter WYY-01-94, INEL, January 17. 